\title{
INTERDISCIPLINARIDADE NO ENSINO DA TRADUÇÃO: FORMAÇÃO POR COMPETÊNCIAS, ABORDAGEM POR TAREFAS DE TRADUÇÃO, TIPOLOGIA TEXTUAL BASEADA EM CONTEXTO'
}

\author{
Maria Lúcia Vasconcellos* \\ Universidade Federal de Santa Catarina \\ Elaine Espindola** \\ Polytechnic University Hong Kong \\ Edelweiss Gysel ${ }^{* * *}$ \\ Universidade Federal de Santa Catarina
}

Resumo: No contexto de formação por competências, este artigo se apoia no modelo de Competência Tradutória (CT) do Grupo PACTE (2003) para estabelecer um diálogo interdisciplinar entre paradigmas cognitivo-

\footnotetext{
${ }^{1}$ Uma versão preliminar deste texto foi apresentada no I Seminário Interdisciplinar das Ciências da Linguagem no Cariri (SIC), 21-23 novembro 2012. Universidade Regional do Cariri (URCA), Crato, CE.

* Maria Lúcia Vasconcellos é Professora Titular do Departamento de Línguas Estrangeiras (DLLE) e pesquisadora/docente do Programa de Pós-Graduação em Estudos da Tradução (PGET) na Universidade Federal de Santa Catarina em Florianópolis, Santa Catarina, Brasil. Realizou em 2012 estágio pós-doutoral na Facultat de Traducció i Interpretació - UAB, Barcelona. Email: maria.vasconcellos@ufsc.br

** Elaine Espindola possui doutorado pela Universidade Federal de Santa Catarina e atualmente é pesquisadora e docente da The Hong Kong Polytechnic University em Hong Kong. Email: elaespindola@gmail.com

*** Edelweiss Gysel é doutoranda do Programa de Pós-Graduação em Estudos da Tradução - PGET na Universidade Federal de Santa Catarina, Florianópolis, Santa Catarina, Brasil. Email: egysel@gmail.com
} 
construtivistas para o ensino de tradução e o modelo de Tipologia Textual Baseada em Contexto (MATTHIESSEN et al., 2007). Nesse espaço teórico, propõe-se um modelo para construção de Unidade Didática (UD) para o desenvolvimento da subcompetência bilíngue para tradutores em formação. Para tanto, a proposta explora a tradução como uma atividade cognitiva, comunicativa e textual (HURTADO ALBIR, 2011) e considera seu ensino a partir da abordagem por tarefa-de-tradução (HURTADO ALBIR, 1999). Essa abordagem é ilustrada com um exemplo prático de desenho de uma UD elaborada para uma disciplina de Introdução à Tradução Especializada, da grade curricular do curso de Secretariado Executivo da Universidade Federal de Santa Catarina. Questões tais como o estabelecimento de objetivos de aprendizagem e seu alinhamento com as tarefas de tradução que compõem a UD são abordadas para essa situação pedagógica específica. Argumenta-se pela possibilidade de desenvolvimento de competências textuais por meio da aquisição de estratégias derivadas da Tipologia Textual Baseada em Contexto para a solução de problemas de tradução de textos de diferentes tipos e configurações contextuais.

Palavras-chave: Desenho curricular baseado em competências; Competência Tradutória; ensino de tradução; enfoque por tarefas de tradução; Tipologia Textual Baseada em Contexto.

\title{
INTERDISCIPLINARITY IN TRANSLATION TEACHING: COMPETENCE-BASED EDUCATION, TRANSLATION TASK-BASED APPROACH, CONTEXT-BASED TEXT TYPOLOGY
}

\begin{abstract}
In the context of competence-based teaching, this paper draws upon the model of Translation Competence (TC) put forward by the PACTE group (2003) to establish a dialogue between cognitive-constructivist paradigms for translation teaching and the model of the Context-based Text Typology (MATTHIESSEN et al., 2007). In this theoretical environment, it proposes a model for the design of a Teaching Unit (TU) for the development of the bilingual competence in would-be-translators. To this end, it explores translation as a cognitive, communicative and textual activity (HURTADO ALBIR, 2011) and considers its teaching from the translation task-based approach (HURTADO ALBIR, 1999). This approach is illustrated through the practical example of the design of a TU elaborated for the subject 'Introduction to Specialized Translation', part of the curricular grid of the program 'Secretariado Executivo' at
\end{abstract}


Universidade Federal de Santa Catarina. Aspects such as the establishment of learning objectives and their alignment with the translation tasks composing the TU are addressed for this specific pedagogical situation. We argue for the development of textual competences by means of the acquisition of strategies derived from the Context-based Text Typology to solve problems arising from the translation of different text types and contextual configurations.

Keywords: Competence based syllabus design; Translation competence; Translation teaching; Translation task-based approach; Context based text typology

\section{Introdução}

Em consonância com o caráter interdisciplinar dos Estudos da Tradução, este artigo busca estabelecer um diálogo entre esse campo disciplinar (especificamente no que tange a Formação de Tradutores) e a Linguística Sistêmico-Funcional (especificamente no que tange a Tipologia Textual Baseada em Contexto). Para tanto, apoia-se no modelo componencial de Competência Tradutória (CT) proposto pelo grupo $\mathrm{PACTE}^{2}$ e na natureza das subcompetências que o integram, para localizar o componente textual em que este trabalho se insere. A seguir no âmbito de aquisição da subcompetência bilíngue, explora a tradução como operação textual e aplica o modelo de Tipologia Textual Baseada em Contexto (MATTHIESSEN et al., 2007) para o desenho de Unidades Didáticas (UDs), a partir do Enfoque por Tarefas de Tradução como marco metodológico.

Para fins de ilustração, apresenta uma UD elaborada para uma disciplina de graduação na Universidade Federal de Santa Catarina (UFSC), que tem por objetivo instrumentalizar o tradutor em formação (por meio de tarefas facilitadoras), a realizar a tradução de específicos tipos textuais. O texto busca mostrar como, por meio da realização de tarefas de tradução informadas pela Tipologia

${ }^{2} \mathrm{O}$ grupo PACTE (http://grupsderecerca.uab.cat/pacte/), da Universidat Autònoma de Barcelona, Espanha, é liderado pela pesquisadora principal, Amparo Hurtado Albir, e realiza pesquisa empírico-experimental sobre a CT e sua aquisição, desde 1997. A base empírico-experimental da pesquisa do PACTE constitui o diferencial de sua proposta. 
Textual Baseada em Contexto é possível desenvolver uma metodologia dinâmica por meio da qual o tradutor em formação aprende a resolver problemas de tradução advindos de diferentes tipos textuais. Nesse contexto, compartilha a experiência de construção e implementação do material didático, com base no quadro teórico-metodológico que informa sua produção, qual seja: Formação de Tradutores com base em competências $\left(\mathrm{PACTE}^{3}\right)$ e Tipologia Textual Baseada em Contexto. As autoras exploram as dimensões da interdisciplinaridade na formação de tradutores, integrando a Tipologia Textual baseada em Contexto ao conceito de Competência Tradutória e implementando esse quadro teórico na construção de uma Unidade Didática ilustrativa, com base na abordagem por tarefas de tradução.

A organização do presente artigo segue esse planejamento geral: após esta introdução, a seção (2) apresenta o quadro teórico em questão (Formação de Tradutores com base em competências) conforme modelo PACTE; Tipologia Textual Baseada em Contexto; parâmetros do Contexto de Situação: ‘campo' e 'Processo Sócio Semiótico' (PSS); a seção (3) apresenta o quadro metodológico (enfoque por Tarefas de Tradução); a seção (4) ilustra a implementação do modelo na construção de uma Unidade Didática (UD); e, finalmente, a seção (5) tece reflexões finais sobre a abordagem por tarefas de tradução e a contribuição da Tipologia Textual Baseada em Contexto para a formação do tradutor.

\section{Quadro teórico}

\subsection{A formação de tradutores baseada em competências - a contribuição do grupo de pesquisa PACTE}

O conceito de Competência Tradutória (CT) tem sido discutido por diferentes teóricos a partir de diferentes perspectivas

${ }^{3}$ Procés d'Aquisició de la Competència Traductora i Avaluació.

Cad. Trad., Florianópolis, v. 37, n $^{0}$ 2, p. 177-207, mai-ago 2017 
(cf. BELL, 1991; PYM, 1992; PRESAS, 1996; KIRALY, 1995; KELLY, 2002; HURTADO ALBIR, 1996, 1999). Hurtado Albir e Alves (2009) apresentam uma breve revisão do debate atual sobre modelos de CT, mostrando como as diversas propostas compartilham o reconhecimento da existência de componentes de CT, em diferentes níveis, sendo, portanto, modelos componenciais (que consideram os componentes da competência tradutória). Esses modelos sugerem como componentes da CT aspectos variados, tais como: conhecimentos linguísticos, textuais, temáticos, culturais, de documentação, etc. Alguns incluem aspectos específicos, como a habilidade de gerar diferentes opções e selecionar uma única delas (cf. concepção 'minimalista' de PYM, 1992); outros apresentam distinções que subjazem o conceito de CT, por exemplo, a distinção entre duas grandes áreas de componentes, conhecimentos epistêmicos e conhecimentos operacionais (cf. a distinção entre conhecimento 'declarativo' e 'operacional' de Presas, 1996); outros ainda incluem um componente estratégico (cf. HURTADO ALBIR, 1996, 1999).

Destacamos uma definição apresentada por Hurtado Albir e Alves (Translation as a Cognitive Activity, 2009), que incorpora o caráter componencial da CT e o fato de ser ela uma habilidade adquirida:

Competência Tradutória (CT): O conjunto de conhecimento, habilidades $e$ atitudes que um tradutor/intérprete deve possuir para realizar adequadamente sua atividade profissional. É um tipo de conhecimento 'experiente' que combina conhecimento declarativo (saber o que) e conhecimento procedimental (saber como), sendo predominantemente procedimental. A competência tradutória é uma habilidade adquirida que passa por diferentes fases, evoluindo desde conhecimento novato até conhecimento 'experiente' (p. 234). ${ }^{4}$

\footnotetext{
${ }^{4}$ Nossa tradução de: "Translation Competence (TC) - The set of knowledge, abilities and attitudes that a translator/interpreter must possess in order to perfom adequately his/her professional activity. It is a type of expert knowledge combining declarative knowledge
}

Cad. Trad., Florianópolis, v. 37， $\mathrm{n}^{0}$ 2， p. 177-207, mai-ago 2017 
Na citação acima, interessam-nos os segmentos salientados em itálicos por dois motivos. Primeiramente, o entendimento de CT como o "conjunto de conhecimento, habilidades e atitudes que um tradutor/intérprete deve possuir para realizar adequadamente sua atividade profissional" encontra eco em outra definição de Hurtado Albir (2011, p. 634) que adotamos em nosso trabalho: "a CT se constitui como um conjunto de sistemas subjacentes de conhecimentos, habilidades e atitudes necessários para traduzir, passíveis de serem adquiridas"; em segundo lugar, a partir da afirmação de que a CT uma habilidade adquirida (não necessariamente um 'dom'), é possível pensar em um projeto pedagógico institucional de formação de tradutores que seja baseado no desenvolvimento dos vários componentes da $\mathrm{CT}$; ou seja, formação de tradutores por competências (HURTADO ALBIR, 2007, 2008).

No modelo do PACTE, a CT é constituída de seis subcompetências, a saber: (i) subcompetência bilíngue; (ii) subcompetência extralinguística; (iii) subcompetência de conhecimentos sobre a tradução; (iv) subcompetência instrumental; (v) subcompetência estratégica; (vi) componentes psicofisiológicos (PACTE, 2003). A Figura 1 abaixo apresenta uma visualização das CT e suas subcompetências:

(knowing that) and procedural knowledge (knowing how), being predominantly procedural. Translation competence is formed by several interrelated components and sub-competences, the most important of which are communicative and textual competence in two (or more) languages; extralinguistic competence (encyclopaedic, cultural and content knowledge as well as knowledge about translation); instrumental competence (the ability to use relevant documentation sources and technological tools applied to translation); professional competence (knowledge about the work market); and strategic competence (related to problem solving and decision- making). Translation competence is an acquired skill which undergoes different phases evolving from novice to expert knowledge" (p. 234). 


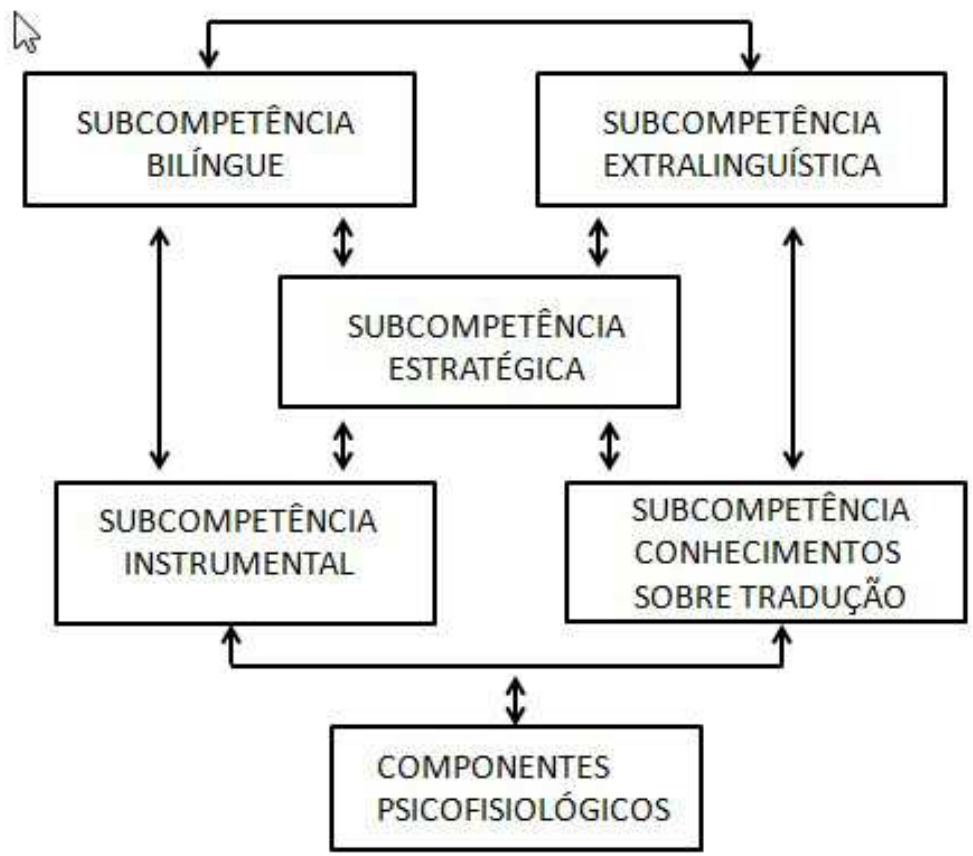

Figura 1: A Competência Tradutória (CT) segundo o modelo holístico de PACTE (HURTADO ALBIR, 2005, p. 28)

Na configuração da CT proposta pelo PACTE, exploramos no presente trabalho a aquisição da subcompetência bilíngue (em seu aspecto textual) e apresentamos uma proposta de Unidade Didática (UD) para sua aquisição, em diálogo com a proposta de Matthiessen (2007) na qual o proponente advoga a centralidade do texto e da análise textual na formação de tradutores. Esse diálogo interdisciplinar na formação de tradutores é abordado a seguir. 


\subsection{A Tipologia Textual Baseada em Contexto}

A partir de uma perspectiva da tradução, Matthiessen (2007, p. 1) apontam a importância de textos em seus contextos de comunicação como a matéria prima de tradutores e intérpretes, bem como a necessidade de desenvolvimento da habilidade de análise textual para tradutores em seu fazer tradutório. Essa habilidade de análise textual confere aos tradutores conhecimento da especificidade de cada tipo textual, o que impacta positivamente na prática de tradução, em termos de adequação dos textos traduzidos às convenções praticadas no contexto de chegada. Segundo os autores, (Ibid., p.14), a área de Estudos da Tradução carece de uma tipologia funcional que seja baseada em parâmetros contextuais, ao invés somente em semânticos e/ou gramaticais.

Com base nesse pressuposto, Matthiessen et al. (2008) apresentam seu modelo de Tipologia Textual Baseada em Contexto, partindo do princípio de que textos, em suas mais variadas formas (escritos, orais, monológicos, dialógicos, multimodais, sinalizados, etc.), realizam atividades sociais (interação) e semióticas (produção de significado) nas quais estão envolvidos indivíduos em sua produção textual. Por realizar uma atividade do indivíduo na produção de significado e interação social, cada texto pode ser categorizado segundo a atividade principal sendo realizada, que se concretiza em atividades do cotidiano como dar/ter aula, trabalhar em um escritório, ir ao supermercado, alimentar um blog, etc.

Em termos mais teóricos, o arcabouço de Tipologia Textual Baseada em Contexto está em consonância com os pressupostos da LSF, uma vez que explora a noção de Contexto de Situação (CS), construto abstrato no qual as variáveis de 'campo', 'relações' e 'modo' são constitutivas do ambiente em que surge o texto; dentre essas variáveis, o 'campo' adquire centralidade no modelo de tipologia textual de Matthiessen (2007), uma vez que a ela estão vinculadas os chamados Processos Sócio-Semióticos (PSSs), definidos como "processo social/semiótico com os quais indivíduos se 
envolvem", em contexto específico, ao produzir um texto (MATTHIESSEN et al. 2010, 95) .

No modelo, a noção de ‘função' textual - central em tipologias textuais 'funcionais', de cunho mais abstrato - é substituída pela noção de PSS, parte integrante do 'campo' que, no modelo, leva em conta não apenas o ‘tópico’ (área de especificidade/domínio ou conteúdo) do texto, mas principalmente o que o autor do texto busca realizar em termos de suas atividades sociais e semióticas. $\mathrm{O}$ modelo categoriza 08 (oito) PSSs, a saber: 'Realizar'; 'Habilitar'; 'Explorar'; 'Expor'; 'Recomendar'; 'Recriar'; 'Reportar.

A Figura 2 apresenta o 'Círculo Discursivo' (SILVA e ESPINDOLA 2013), idealizada por Matthiessen (2007) para representar os PSSs e os tipos de texto que os realizam. Esse círculo apresenta os oito PSSs (primeira camada interna do círculo a partir de seu centro); as demais camadas oferecem diferentes combinações desses PSSs e as variáveis de modo e turno, com exemplos concretos de tipos textuais realizando os PSSs. Como por exemplo, na camada mais exterior do círculo, realizam-se os textos monólogos/escritos, como reportagem, romance, etc. Os 8 (oito) PSSs encontram-se na parte central do círculo, camada imediata e diretamente vinculada ao construto 'Campo' - epicentro do modelo - constituindo o ponto de partida para a produção (ou recepção) textual: o que o PSSs está realizando no texto em específico ${ }^{6}$ ?

\footnotetext{
${ }^{5}$ Nossa tradução de: "The activity is the social and/ or semiotic process that the interactants in the context are engaged in".

${ }^{6}$ Para um maior detalhamento das definições de cada PSS, sugerimos consulta ao dicionário Key Terms in Sistemic Funcitional Linguistics, Matthiessen, C. M. I. M., Teruya, K., Lam, M. (2010), publicado em Londres, pela editora Continuum International Publishing Group.
} 


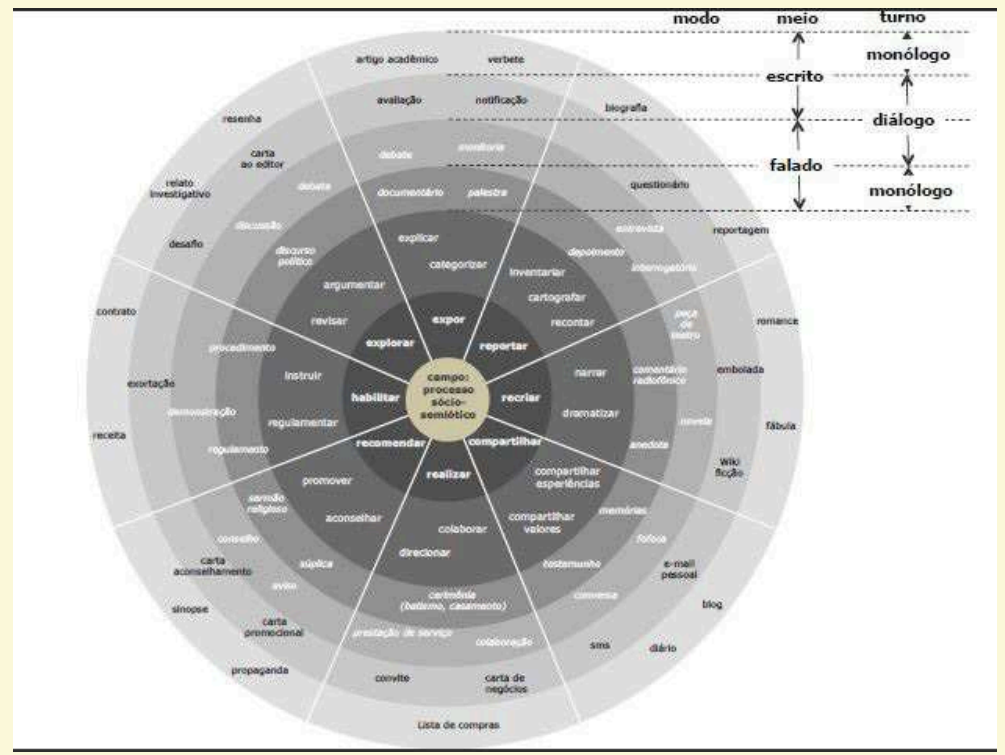

Figura 2: Tradução da Esfera de Processos Sócio-Semióticos (MATTHIESSEN, TERUYA e WU, 2007) por Silva e Espindola (2013).

Os PSSs são considerados ferramentas conceituais disponíveis ao tradutor, para quem tais ferramentas podem ser consideradas como base estratégica para o reconhecimento do tipo a que pertence o texto a ser traduzido: torna-se possível para o tradutor identificar a natureza Sócio Semiótica do texto nas línguas em relação tradutória e as realizações típicas de cada PSS, o que é essencial para a fase de 'reconhecimento de texto' que precede o início da tradução propriamente dita, fornecendo apoio para a sua execução. A partir desse reconhecimento, o tradutor estaria em posição de buscar, no contexto/língua de chegada ao qual pertencerá o texto traduzido, as realizações típicas de cada PSS, possibilitando assim a produção textual apropriada para cada processo socio-semiótica em questão.

Uma das vantagens da Tipologia Textual Baseada em Contexto é que ela possibilita uma classificação contínua e flexível de textos enquanto realização de ações desenvolvidas por indivíduos envol- 
vidos no contexto, incluindo-se aqueles produzidos (ou por ainda serem produzidos) na atualidade, como por exemplo, textos da mídia digital, tipicamente não classificados nas tipologias textuais tradicionais, no contexto dos Estudos da Tradução (HERRING et al., 2006, 2004).

Uma outra questão relevante que se coloca com relação à análise textual nos termos aqui propostos diz respeito à possibilidade de sobreposição de tipos textuais, o que é apontado por Bell (1991), gerando um hibridismo que se configura como uma questão de difícil solução nas tipologias tradicionais. Com relação a esse aspecto, a Tipologia Textual Baseada em Contexto consegue dar conta de tal hibridismo, uma vez que não apenas reconhece a possibilidade de sua existência em textos, como o justifica: "os tipos de Situação definidos por esses oito PSSs podem se sobrepor e se mesclar uns com os outros; dessa maneira, todos são permeáveis" (MARTIN e MATTHIESSEN, 2012, p. 6). Como afirma Bell (Ibid.), mesmo uma tipologia hierárquica como a que propõe não dá conta de explicar e descrever a sobreposição de tipos de textos, o que nem sequer tinha sido mencionado na tipologia de Reiss (1971). Isso, sem dúvida é uma outra contribuição relevante para os estudos textuais, monolíngues, bilíngues, multilíngues ou estudos de textos em relação tradutória.

\section{Quadro Metodológico}

\subsection{Enfoque por tarefas de tradução}

Como explica Hurtado Albir (2005, p. 42), o enfoque por tarefas surge no âmbito da didática de línguas estrangeiras, em meados da década de 1980, no contexto do reconhecimento da necessidade de um currículo 'integralizador', capaz de integrar as dimensões 'objetivos', 'conteúdos', 'metodologia' e 'avaliação'. O enfoque por tarefas surge com vistas a dotar o desenho curricular de um caráter globalizante e a considerar o aluno como 'protagonista do 
ato didático', incorporando informações por ele fornecidas, numa negociação contínua entre professores e estudantes. ${ }^{7}$

Hurtado Albir (2005) considera a "tarefa como a unidade organizadora do processo de aprendizagem" (p. 43) e lista as seguintes vantagens dessa abordagem (2007): a) ela pode simular situações reais de tradução utilizando material autêntico (textos reais) relacionado ao mundo profissional; b) ela proporciona uma metodologia ativa e une conteúdo e metodologia, pois ativa uma sequência contínua de atividades nas quais o aluno aprende fazendo; c) ela permite o aprendizado com enfoque no processo, pois o aluno realiza uma sequência de trabalho, desde a pré-tarefa até a tarefa final; d) ela possibilita a aquisição não somente dos princípios que regem a tradução, mas também das estratégias para resolver problemas tradutórios; e) ela é representativa do ensino com enfoque no aluno, o qual é o protagonista na realização das tarefas e o professor é apenas um guia facilitador; e f) ela é flexível, pois pode se adequar as necessidades dos alunos, além disso, ela integra a avaliação formativa, na qual o aluno se autoavalia durante todo o processo se tornando mais autônomo.

Por entender que os pressupostos do enfoque por tarefas são de interesse para a didática de tradução, Hurtado Albir propôs um enfoque por tarefas de tradução (cf. HURTADO ALBIR, 1993, 1995, 1996, 1999, 2005) e definiu a tarefa de tradução como "uma unidade de trabalho na sala de aula, representativa da prática tradutória, dirigida intencionalmente à aprendizagem da tradução e desenhada com um objetivo concreto, estrutura e sequência de trabalho" (HURTADO ALBIR, 1999, p. 56). O Quadro 1 apresenta a estruturação da tarefa de tradução (HURTADO ALBIR, 2005):

\footnotetext{
7 Para explicar o "enfoque por tarefas" e sua inspiração no conceito de "tarefa" no contexto de ensino de Línguas Estrangeiras (LE), Hurtado Albir (Ibid., p. 42) destaca as contribuições de Candlin e Murphy (1987), Nunan (1989), Hutchinson (1991), Zanón (1990), entre outros.
}

Cad. Trad., Florianópolis, v. 37, no 2, p. 177-207, mai-ago 2017 


\begin{tabular}{|l|}
\hline \multicolumn{1}{|c|}{ Estruturação de cada tarefa } \\
\hline Objetivo: \\
\hline Material de apoio: \\
\hline Desenvolvimento da tarefa: \\
\hline Ficha 1: \\
\hline Ficha 2: \\
\hline Avaliação: \\
\hline Comentários: \\
\hline Referências: \\
\hline
\end{tabular}

Quadro 1: Estruturação da Tarefa de tradução segundo Hurtado Albir (2005)

Como mostra o Quadro 1, o objetivo para cada tarefa de tradução é estabelecido, juntamente com os materiais utilizados, incluindo-se aqui material de apoio para informar a execução da tarefa, textos para traduzir, textos paralelos, fichas de trabalho, etc.; o desenvolvimento da tarefa é feito em termos de atividades, o que no quadro acima é feito em termos de Fichas $(1,2,3 \ldots)$. A tarefa de tradução poderá também ter uma etapa de avaliação e comentários sobre o próprio desenvolvimento da tarefa, com sugestões de modificações, continuações e até mesmo tarefas posteriores, aumentando gradativamente o envolvimento dos alunos no planejamento do material didático, com vistas a promover a gradual autonomia do tradutor-em-formação; além disso, há a possibilidade de se incluir uma lista de referências teóricas em que a tarefa se baseia.

Conforme Hurtado Albir, a "tarefa de tradução torna-se o eixo principal da elaboração da unidade didática", que é “estruturada em diferentes tarefas facilitadoras preparatórias para a(s) tarefa(s) final(ais)" (2005, p. 44).

A seguir, a construção de uma Unidade Didática. 


\subsection{Construção/estruturação de uma Unidade Didática (UD)}

A UD é organizada em torno de diferentes tarefas de tradução, que podem assim ser de natureza diferente: algumas tarefas, como mencionado acima, têm caráter preparatório e intermediário, incluindo tarefas de aprendizagem (centradas no desenvolvimento de uma capacidade, uma habilidade ou um conteúdo disciplinar), tarefas de integração (que ativam vários componentes de uma competência) e, pelo menos, uma tarefa integradora (que ativa uma ou várias competências específicas e ao menos uma competência geral/transversal) (HURTADO ALBIR, 2015, p. 12-13). Busca-se assim que o aluno aprenda a fazer fazendo.

Como explica Hurtado Albir (Ibid.), "essas tarefas são de diversos tipos e servem para que o aluno adquira conhecimentos e habilidades e desenvolva atitudes que lhe possibilitem adquirir as competências para levar a cabo a tarefa final com êxito"8 (p. 13). $\mathrm{Na}$ tarefa final, o aluno terá de demonstrar que adquiriu as competências necessárias e que alcançou os objetivos de aprendizagem para os quais a UD foi construída. Existe, pois, uma progressão entre as diversas tarefas, em direção a uma maior autonomia do aluno na realização da tarefa final, de modo mais autônomo.

Em algumas UDs, entretanto, pode não haver uma tarefa final específica, ou podem ser propostas tarefas posteriores à tarefa final (como, por exemplo, refletir sobre sua própria tradução, para que possa entender o processo de tradução, pensar sua aprendizagem e, posteriormente, poder elaborar justificativas para as soluções encontradas para os problemas tradutórios). Adicionalmente, a UD poderá também incluir uma sessão denominada "Material de apoio" (cf. HURTADO ALBIR, 2015, p. 14), contendo conceitos úteis para o alcance dos objetivos de aprendizagem propostos.

O Quadro 2 mostra a estrutura da UD, organizada em torno de diferentes tarefas de tradução e desenhada com vistas ao alcance

\footnotetext{
${ }^{8}$ Nossa tradução de: "Estas tareas son de diverso tipo y sirven para que el estudiante adquiera conocimientos y habilidades, y desarrolle actitudes que le posibiliten adquirir las competencias cifras para llevar a cabo la tarea final con éxito" (HURTADO ALBIR, 2015, p. 13).
}

Cad. Trad., Florianópolis, v. 37, n⿳2 2, p. 177-207, mai-ago 2017 
de um (ou mais) objetivo de aprendizagem (HURTADO ALBIR, 1999, p. 56).

\begin{tabular}{|l|}
\hline \multicolumn{1}{|c|}{ Unidade Didática (UD) } \\
\hline Objetivo específicos (de aprendizagem): \\
\hline Estruturação da unidade: \\
\hline Tarefa 1: \\
\hline Tarefa 2: \\
\hline Tarefa ... \\
\hline Tarefa final: \\
\hline
\end{tabular}

Quadro 2: Estrutura da Unidade Didática (UD)

Cumpre esclarecer dois aspectos: (i) cada Tarefa tem a possibilidade de ser explorada mais detalhadamente em Fichas; (ii) tipicamente, cada UD termina com uma reflexão para que o aluno tenha a oportunidade de pensar sobre o que aprendeu na UD. Com relação à dimensão reflexiva da tarefa final, é importante salientar que tal atividade visa ajudar o aluno a forma a acompanhar a evolução de seu processo de aprendizagem e a traçar um plano de ação para sua melhoria; esse exercício de reflexão busca, em última instância, promover a autoavaliação e a autorregulação do aluno (cf. VILLARDÓN, 2006; BIGGS, 2005), que por meio dela desenvolve técnicas de aprendizagem metacognitiva de supervisão e automonitoramento de elevado grau de generalização, o que vem por lhe permitir abordar com sucesso novas situações similares utilizando as estratégias aprendidas.

Esse último aspecto evidencia um ponto interessante da proposta de Hurtado Albir: as tarefas de tradução - desenhadas de tal forma a permitir a progressão rumo a uma maior autonomia na realização da tarefa final - proporcionam ao aluno espaço de reflexão sobre sua própria prática, de tal forma a torna-lo consciente de suas estratégias e partícipe ativo de seu processo educativo; além disso, ao dar espaço para a autoavaliação, a tarefa de tradução enfatiza o 
controle pelo aluno, que monitora, direciona e regula as suas ações em direção à automelhoria. Em última instância, oferece suporte ao aluno para se tornar profissional competente, capaz de avaliar sua prática para analisá-la e melhorá-la ao longo de sua vida acadêmica e laboral.

Como ilustração, apresentamos abaixo a construção de uma UD: "Tradução de textos Corporativos: Memorandos" (versão completa no Apêndice 1), parte componente da disciplina Tradução e Versão do Inglês 1 - Introdução à Tradução Especializada ${ }^{9}$.

\section{Ilustração}

A UD apresentada como ilustração foi elaborada para uma situação pedagógica específica, a saber, a disciplina de tradução LLE 5166 do Curso de Secretariado Executivo, da Universidade Federal de Santa Catarina. Conforme a grade curricular, essa disciplina integra a sétima fase, ou seja, o penúltimo semestre do curso, o que define como pré-requisito um conhecimento intermediário da língua inglesa, ou seja, capacidade de examinar, entender, analisar e refletir sobre variados textos em inglês. Além disso, sendo a disciplina parte do curso de Secretariado Executivo, parte-se do pressuposto de familiaridade dos alunos com textos da área corporativa: tal conhecimento prévio foi confirmado por meio de questionário diagnóstico e serviu de base e critério para a seleção de textos para as UDs.

Essa breve contextualização tem relevância em termos teóricos: conforme esclarece Hurtado Albir (1999, p. 12) a didática de tradução proposta pelo Grupo PACTE é de cunho cognitivo-construtivista e, portanto, considera o aluno como protagonista,

\footnotetext{
${ }_{9}^{9}$ Adotamos aqui a definição de tradução especializada proposta por Hurtado Albir (1999, p.250): “[...] la traducción de textos especializados (técnicos, científicos, jurídicos, económicos, administrativos). En Traductología y en didáctica de la tradución es preferible ampliar la denominación a todos los casos de especialización: Traducción técnica y científica, Traducción jurídica, Traducción audiovisual, Traducción literaria [...]”.
}

Cad. Trad., Florianópolis, v. 37， $\mathrm{n}^{0}$ 2， p. 177-207, mai-ago 2017 
coparticipante ativo e corresponsável no processo de aprendizagem. Por essa razão, a elaboração de UDs leva em consideração o contexto acadêmico em que os alunos estão inseridos, bem como seu conhecimento prévio.

A UD ilustrada é a UD410: "Tradução de textos Corporativos: Memorandos", parte do elenco de seis Unidades Didáticas da disciplina:

Unidade Didática 1 (UD1): Introdução à Tipologia Textual baseada em Contexto

Unidade Didática 2 (UD2): Métodos de Documentação e Uso de TICs

Unidade Didática 3 (UD3): Necessidades do Mercado Corporativo e Perfil do Tradutor

Unidade Didática 4 (UD4): Tradução de Textos da Área Corporativa: Memorandos

Unidade Didática 5 (UD5): Tradução de Textos da Área Corporativa: Atas

Unidade Didática 6 (UD6): Diretrizes para Portfólio, Relatório e Autoavaliação.

Cumpre observar que, no contexto do elenco de UDs da disciplina, ao trabalhar a UD4 os alunos já estavam familiarizados com a abordagem por 'tarefas de tradução' e já haviam se apropriado da noção de 'Processo Sócio Semiótico' (PSS).

Tomando os objetivos de aprendizagem da disciplina como ponto de partida, elaboramos um perfil de competências a elas associados (HURTADO ALBIR, 2007):

- Competência pré-tradutória (HURTADO ALBIR 1999, p. 58), ou "Fase de orientação": capacidade de situar o texto;

${ }^{10}$ Cumpre observar que a proposta de material didático elaborado para a disciplina em questão é ainda provisória, encontrando-se em seu estágio experimental. 
- Competência textual: componente da sub-competência bilíngue e contrastiva, relacionada à solução de problemas de tradução que surgem de diferentes campos textuais e dos elementos que os caracterizam, utilizando estratégias apropriadas;

- Competência instrumental: programação da documentação necessária para tradução dos diferentes campos de aquisição de conhecimento temático.

Os objetivos específicos da UD4 estão alinhados ao perfil de competências textuais ("Ao final da Unidade Didática, o aluno será capaz de...”):

i. Reconhecer o tipo textual de cada texto conforme a Tipologia Textual Baseada em Contexto;

ii. Propor uma tradução direta (da língua estrangeira para a língua materna) de um texto específico;

iii. Refletir sobre o próprio processo de aprendizado durante a realização da UD'.

As tarefas que estruturam a UD são elaboradas visando então o alcance desses objetivos de aprendizagem, como detalhado a seguir.

\begin{tabular}{|ll|}
\hline Tarefa 1 & $\begin{array}{l}\text { Reconhecimento da Tipologia Textual de } \\
\text { memorandos } \\
\text { [tarefa preparatória centrada no desenvolvimento de } \\
\text { uma habilidade] }\end{array}$ \\
Tarefa 2 & $\begin{array}{l}\text { Proposta de tradução direta (da língua } \\
\text { estrangeira para a língua materna) de um texto } \\
\text { específico } \\
\text { [tarefa de integração, ativando componentes de uma } \\
\text { competência] }\end{array}$ \\
&
\end{tabular}


Tarefa final Reflexão sobre o processo de aprendizado na
UD4 [tarefa posterior à tarefa final, com reflexão sobre sua própria tradução]

Quadro 3: Estrutura de uma Unidade Didática

Cada Tarefa da UD4 contém Fichas a serem trabalhadas pelo aluno. Na Ficha 1 da Tarefa 1, dois Memorandos são apresentados aos alunos, tratando de assuntos diversos e contendo diferentes formatações. Os alunos são encorajados a reconhecer o tipo textual ou os tipos textuais presentes em cada Memorando com base nas explicações e tarefas já realizadas anteriormente na UD 1 - Introdução à Tipologia Textual Baseada em Contexto. A intenção aqui é (i) levar o aluno a perceber como a Tipologia Textual Baseada em Contexto difere de outras tipologias e (ii) como essa tipologia pode auxiliar a compreensão e, consequentemente, a tradução de textos. Após a classificação dos textos, os alunos são estimulados a compartilhar e comparar suas respostas com colegas e refletir sobre as diferenças e semelhanças.

Ainda na Tarefa 1 é oferecido 'Material de Apoio', que serve como informação conceitual para fundamentar e auxiliar a realização das atividades. Após a leitura do Material de Apoio os alunos retomam os textos na Ficha 2, agora com um olhar mais informado, para classificar os memorandos de acordo com a Tipologia Textual Baseada em Contexto. Feito isso, eles são levados a refletir sobre eventuais mudanças na primeira e na segunda classificação, assim como a analisar os textos mais detalhadamente a fim de observar a emergência (ou não) de padrões textuais.

A Ficha 1 da Tarefa 2 solicita ao aluno uma proposta de tradução de um memorando de sua própria escolha (utilizando as ferramentas e meios que julgar necessários para realizar a tradução). É dado um tempo determinado para a tradução e revisão do texto, nada muito extenso, dada a curta extensão dos textos. Após a proposta de tradução feia pelo aluno, a Ficha 2 o incentiva à reflexão sobre os problemas tradutórios, as ferramentas utilizadas e as so- 
luções encontradas, assim como as justificativas para tais soluções. Cumpre esclarecer que não é a intenção aqui avaliar as traduções, e sim refletir sobre o processo de sua produção, incentivando o aluno a se autoconhecer como tradutor identificando seus conhecimentos, portanto suas destrezas, assim como avaliando e reconhecendo suas dificuldades (autoavaliação).

A Tarefa Final concentra-se na reflexão sobre o aprendizado. A Ficha 1 solicita ao aluno uma posição quanto à utilidade do conhecimento a respeito dos PSSs no processo tradutório. Na Ficha 2 ele é incentivado a compartilhar suas respostas e impressões sobre toda a UD com seus colegas. Ao final da UD, é feita uma discussão sobre as experiências de reconhecer os tipos textuais conforme a Tipologia Textual Baseada em Contexto e, instrumentalizado com esse reconhecimento, de realizar a tradução de um memorando.

Por meio das orientações dispostas antes de cada Ficha e das perguntas contidas nas próprias Fichas, o aluno sabe exatamente o procedimento a seguir a fim de completar a Tarefa. Nesse cenário, o professor se torna um 'facilitador' (cf. KIRALY, 2000), ressaltando apenas alguns detalhes mais importantes do 'Material de Apoio' e respondendo a eventuais dúvidas os alunos. Ao mesmo tempo em que essa metodologia respeita o tempo de assimilação e aprendizado de cada aluno, ela o torna bastante autônomo, coparticipante de seu processo de aprendizagem e por ele corresponsável. Além disso, como essa ilustração buscou mostrar, os objetivos de aprendizagem são contemplados nas atividades. Ao final de cada UD, o aluno é solicitado a entregar a unidade completa, que receberá comentário formativo por parte do professor, não apenas com relação ao produto (ou seja, a tradução proposta pelo aluno), mas, sobretudo, em relação, ao processo pelo qual o aluno passou a fim de completar a UD, suas reflexões e as justificativas para as soluções encontradas para os problemas tradutórios. Com base nas repostas a essas perguntas, que evidenciam o trabalho do aluno e sua construção de conhecimento em cada UD é que o professor avalia o aprendizado de cada aluno ${ }^{11}$.

${ }^{11}$ A questão da avaliação está fora do escopo deste artigo. Para uma discussão da avaliação no contexto da formação por competência, ver Galán-Manas e Hurtado Albir, 2015. 


\section{Reflexões finais}

O presente artigo buscou articular (i) o modelo de aquisição da Competência Tradutória (CT) do PACTE e seus desdobramentos para a formação de tradutores por competências, (ii) a proposta de didática de tradução por tarefas de tradução e (iii) a Tipologia Textual Baseada em Contexto na situação pedagógica específica de uma disciplina de Introdução à Tradução Especializada, com enfoque na aquisição da subcompetência bilíngue. A Unidade didática (UD) apresentada como exemplo prático buscou ilustrar essa articulação teórico-metodológica por meio da construção de tarefas de tradução elaboradas em alinhamento com os objetivos textuais propostos.

Para tanto, além das bases teóricas e metodológicas, o artigo apresentou a descrição da construção Unidade Didática em questão (na íntegra no Apêndice 1), explorando sua organização em torno de tarefas de tradução. Buscou-se mostrar que, por meio de tarefas de tradução, é possível desenvolver uma metodologia viva na qual o tradutor em formação não apenas aprende fazendo e captando princípios, como também aprende a resolver problemas e a refletir metacognitivamente sobre seu processo de aprendizagem. Com relação a essa dimensão reflexiva da tarefa, é importante salientar que essa atividade visa ajudar o aluno a acompanhar a evolução de seu processo de participação ativa em sua aprendizagem e a traçar um plano de ação para sua melhoria; esse exercício de reflexão busca, em última instância, promover a autoavaliação e a autorregulação do aluno (cf. VILLARDÓN, 2006; BIGGS, 2005), que desenvolve técnicas de aprendizagem metacognitiva de supervisão e automonitoramento, o que vem por lhe oferecer suporte para se tornar profissional competente, capaz de avaliar sua prática para analisá-la e melhorá-la ao longo de sua vida acadêmica e laboral.

Finalmente, argumentou-se pela possibilidade de desenvolvimento de competências textuais por meio de estratégias derivadas da proposta de Tipologia Textual Baseada em Contexto para a solução de problemas de tradução que surgem da manipulação 
de diferentes tipos textuais. Essa Tipologia possibilita uma classificação contínua e flexivel de textos enquanto realização de ações desenvolvidas por indivíduos envolvidos no contexto, incluindo-se aqueles produzidos ou por ainda serem produzidos (como por exemplo, textos da mídia digital), tipicamente não classificados nas tipologias textuais tradicionais, no contexto dos Estudos da Tradução (HERRING et al., 2006; 2004); além disso, a análise textual nos termos aqui propostos possibilita dar conta da questão de hibridismo textual, uma vez que não apenas reconhece a possibilidade de sua existência em textos, como o justifica: "os tipos de Situação definidos por esses oito PSSs podem se sobrepor e se mesclar uns com os outros; dessa maneira, todos são permeáveis" (MARTIN e MATTHIESSEN, 2012, p. 6).

Nesse sentido, buscou-se evidenciar a contribuição da Tipologia Textual Baseada em Contexto como uma ferramenta útil para o entendimento da relação texto-contexto e o reconhecimento da filiação tipológica de textos, enquanto instrumento para orientar decisões tradutórias, no contexto de formação de tradutores por competências, em um paradigma cognitivo-construtivista para o ensino de tradução.

\section{Referências}

BELL, Roger. T. Translation and Translating. Londres: Longman, 1991.

BIGGS, John. B. Calidad del aprendizaje universitário. Madrid: Narcea, S.A. de Ediciones, 2005.

GALÁN- MAÑAS, Anabel; HURTADO ALBIR, Amparo. Competence Assessment procedures in translator training. In: The Interpreter and Translator Trainer. Manschester: St. Jerome Publishing, v. 9, n. 1, p. 63-82, 2015. 
HERRING, Susan. C. Content analysis for new media: Rethinking the paradigm. In: New Research for New Media: Innovative Research Methodologies Symposium Working Papers and Readings. Minneapolis: University of Minnesota School of Journalism and Mass Communication, p. 47-66, 2004. Disponível em: < http:// ella.slis. indiana.edu/ herring /newmedia.pdf $>$. Acesso em: 03/02/2015

.; SCHEIDT, Lois A.; KOUPER, Inna; WRIGHT, Elijah. A longitudinal content analysis of weblogs: 2003-2004. In: TREMAYNE, M. (Ed.). Blogging, Citizenship, and the Future of Media. London: Routledge, 2006. p. 3-20.

HURTADO ALBIR, Amparo. Un nuevo enfoque de la didáctica de la traducción: Metodología y diseño curricular. In: Les langues étrangères dans l'Europe de l'acte Unique. Barcelona: ICE; Universitat Autònoma de Barcelona, 1993.

. Didáctica de la traduccíon. In: BEL, E. (Ed.) Le masque et la plume. Traducir: reflexiones, experiencias y prácticas. Sevilha: Universidade de Sevilha, 1995.

. La enseñanza de la traducción. Castelló: Universitat Jaume I, 1996.

. Enseñar a traducir: metodología en la formación de traductores e intérpretes. Madrid: Edelsa, 1999.

. A aquisição da competência tradutória: aspectos teóricos e didáticos. In: PAGANO, A.; MAGAlHÃES, C.; ALVES, F. (Org.). Competência em tradução: cognição e discurso. Belo Horizonte: UFMG, 2005. p. 19-57.

. Competence-based Curriculum Design for Training Translators. In: The Interpreter and Translator Trainer. Manchester: St. Jerome Publishing, v. 1, $\mathrm{n}$. 2, p. 163-195, 2007.

. Competénce em traduction et formation par compétences. In: TTR: traduction, terminologie, redaction, Canada: Association canadienne de traductologie, v. 21, n.1, 2008.

. Traducción y traductología. Introducción a la traductología. Ed. rev. Madrid: Cátedra, 2001/2011. 
. Aprender a traducir del francés al español. Competencias y tareas para la Iniciación a la traducción. Madrid: Edelsa, D.L, 2015.

HURTADO ALBIR, Amparo e ALVES, Fabio. Translation as a cognitive Activity. In: MUNDAY, Jeremy (Ed.). The Routledge Companion to Translation Studies. Ed. rev. NewYork: Routledge, 2009. p. 54-73.

KELLY, Dorothy A. Un modelo de competencia traductora: bases para el diseño curricular. In: Puentes Hacia Nuevas Investigaciones en la Mediación Intercultural 1, p. 9-20, 2002.

. A Handbook for Translator Trainers. Oxford: Alden Press, 2005.

KIRALY, Don. Pathways to translation: Pedagogy and process. Kent: Kent State University Press, 1995.

. A Social Constructivist Approach to Translator Education: Empowerment from Theory to Practice. Manchester; Northampton: St. Jerome Publishing, 2000.

MARTIN, Jim R.; MATTHIESSEN, Christian M.I.M. Modelling and Mentoring: teaching and learning from home through school. In: TESOL. Columbus: Ohio State University Student Union, 2012.

MATTHIESSEN, Christian M. I. M. English grammar through text: text typology and grammatical patterns. Hong Kong: University of Hong Kong, 2007. [Department of Linguistics, Macquarie University. Centre for Language in Social Life, Macquarie University. Systemic Meaning Modelling Group. Halliday Centre for Intelligent Applications of Language Studies.]

. Ideas and new directions. In: HALLIDAY, M. A. K.; WEBSTER, Jonathan. J. (Ed.). Continuum Companion do systemic Functional Linguistics. Great Britain: MPG Books Group, 2009. p. 12-58.

.; KAZUHIRO, Teruya; CANZHONG, Wu. Multilingual studies as a multi-dimentional space of interconnected language studies. In: Jonathan Webster, London/New York: Continuum, 2008. 
.; KAZUHIRO, Teruya; LAM, Martin. Key Terms in Sistemic Funcitional Linguistics. London; New York: Continuum International Publishing Group, 2010.

PROCÉS D'AQUISICIÓ DE LA COMPETÈNCIATRADUCTORA I AVALUACIÓ - PACTE. Building a translation competence model. In: ALVES, Fabio. (Ed.). Triangulating translation: perspective in process oriented research. Amsterdam: John Benjamins, 2003. p. 43-66.

PRESAS, Marisa. Problemes de traducció $i$ competência traductora. Bases per a una pedagogia de la traducció. Tesis doctoral. Universitat Autònoma de Barcelona, 1996.

PYM, Antony. Translation and Text Transfer. An Essay on the Principles of Intercultural Communication. Frankfurt; Berlin; Bern; New York; Paris; Vienna: Peter Lang, 2010. Tarragona: Intercultural Studies Group. 1992. Revised online version. Google Books version of first edition.

REISS, Katharina. Möglichkeiten und Grenzen der Übersetzungskritik. Munich: Max Hueber, 1971.

SILVA, Wagner R.; ESPINDOLA, Elaine B. Afinal, o que é gênero textual na linguística sistêmico-funcional? In: Pensar e produzir inovação em linguística. ANP, Vol. 1 N. 34, 2013. Disponível em: < http://www.anpoll.org.br/revista/ index.php/ revista/article/view/672/697 > . Acesso em 30 mar. 2015.

VILLARDÓN, Maria, L. Evaluación del aprendizage para promover el desarollo de competencias. In: Education siglo XXI, v. 24, p. 57-76, 2006.

Recebido em: 26/09/2016 Aceito em: 16/12/2016 Publicado em maio de 2017 


\section{APÊNDICE 1}

UNIDADE DIDÁTICA 4 (UD4): disciplina LLE5166, Curso de Secretariado Executivo, Centro de Comunicação e Expressão (CCE), Universidade Federal de Santa Catarina (UFSC), Brasil.

UNIVERSIDADE FEDERAL DE SANTA CATARINA CENTRO DE COMUNICAÇÃO E EXPRESSÃO

DEPARTAMENTO DE LÍNGUA E LITERATURA ESTRANGEIRAS

UNIDADE DIDÁTICA 4. TRADUÇÃO DE TEXTOS CORPORATIVOS: MEMORANDOS

(UD4)

OBJETIVOS: 1. Reconhecer o tipo textual de cada texto de acordo com a Tiplogia Textual baseada em Contexto

2. Propor uma tradução direta

3. Refletir sobre o processo de aprendizado durante a UD

\section{Estrutura da Unidade}

Tarefa 1. Reconhecimento da Tipologia Textual de memorandos

Tarefa 2. Proposta de tradução direta

Tarefa final. Reflexão sobre o processo de aprendizado na UD4

TAREFA 1: Reconhecimento da Tipologia Textual de memorandos

Leia os textos da FICHA 1 (Reconhecendo os PSSs de Memorandos) e indique na célula da direita qual é o PSS de cada um, se houver mais de um PSS indique-os também. Converse com um colega sobre suas respostas e compare-as. A seguir, responda à pergunta ao final da FICHA. 


\section{Ficha 1. Reconhecendo os PSSs de Memorandos}

\begin{tabular}{|l}
\hline TEXTO \\
\hline \\
Crafston Solutions, Inc. \\
(972) 4631549 \\
100 Central, Rowlett, TX 75083
\end{tabular}

\section{Memo}

To: Department Heads

From: Debora Lymn

Date: December 10, 2006

Subject: Annual Borus Leave for Employees with Outstanding Performane

Slarting January 1, we will introduce the following moditication in our company policy with regard to armual leave: every year one employee from each department will be awarded special annual bonus leave for outstanding performance.

The eligible employees will have additional five (5) days of annual leave credited on January 15. The bonus leave will be accounted for separately and will remain available until used. notwithstanding ary other limitation of the total number of days of annual leave that may be carried forward.

We will have a meeting on December 15 at $10-00 \mathrm{am}$. to discuss the results of the 2006 performance evaluation and approve the final list of employees eligible for the bonus. The announcement to the employees will follow the meefing. If you have any questions or comments, please let me know before the meeting. 
Maria Lúcia Vasconcellos, Elaine Espindola \& Edelweiss Gysel

\section{MEMORANDUM FOR THE PRESIDENT}

SUBJECT: Neclear Stockpile Certification

in response to your cirection to conduct as annual certification of the nuclear weapons steckpilc, we have tboroughly reviewed the safety and reliability of the stockpile. The nuclear stockpile has no safety or reliability concerns that require underground nuclear testing at this time. Problens that have arisen in the stockpile are being addressed and rosolved without underground nuelear tasting to crsure the stockpile romains safe and reliable. In reaching this conciusion, we have obtained the sdvice of the Directors of the National Weapons Laboratories, the Comnaades in Chief, United Statcs Strategic Comnand, and fie Nuclear Weapons Council. We will contiane to iniorm you annully on the safety and reliability of the nuclear weapons stockpile in the sibsenoe of underyround muelear testing, and it the context of the DCE'? Stockpile Stowsrdship Plan.
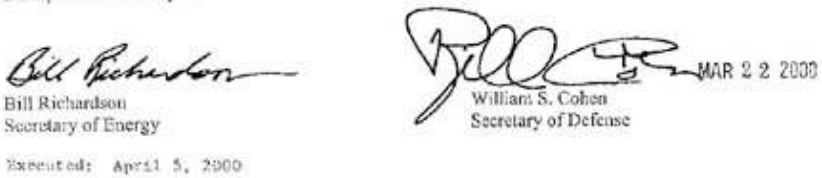

Hexpetil: Apris s, 2300

Depois de comparar suas respostas com as de seu colega, quais foram as semelhanças entre as respostas? Quais foram as diferenças? Vocês chegaram a um acordo? Alguém mudou de opinião? Por que?

\section{Resposta:}

\section{MATERIAL DE APOIO 1. Reconhecimento da Tipologia Textual de memorandos}


Relembrando: "os Processos Sócio Semióticos" (PSS's) conferem significado ao texto. Observe que um texto realiza um PSS típico para aquele domínio, mas em sua estrutura pode conter segmentos que podem realizar outros PSS's, sendo os textos em que isso acontece denominados textos híbridos. Para o reconhecimento do Texto de Partida (TP), é útil basear-se na Figura 1 (Oito processos sócio-semióticos).

No quadro abaixo os PSS's estão representados na segunda esfera: Explorar, Expor, Reportar, Habilitar, Recomendar, Recriar, Realizar e Compartilhar.

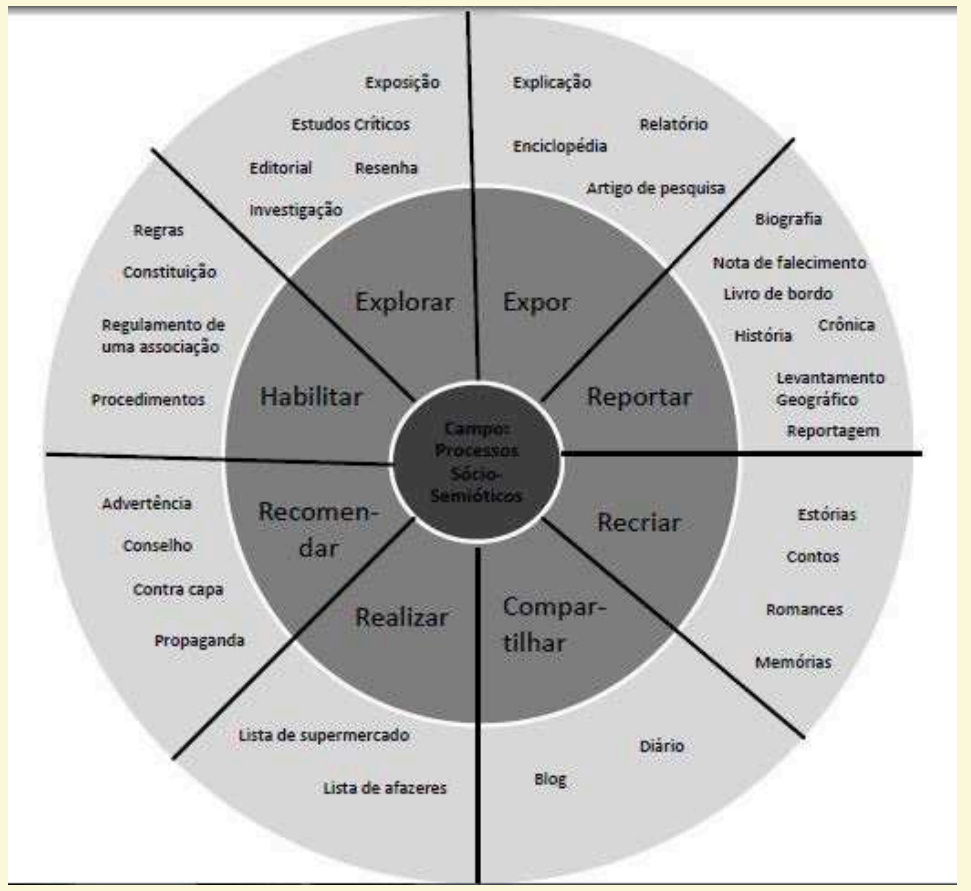

Depois de relembrar o que são os PSSs com a ajuda do Material de Apoio, coloque abaixo suas classificações, agora informadas, dos memorandos já vistos na FICHA 1. Após completar a FICHA 2, responda as perguntas nas células indicada 


\begin{tabular}{|l|l|}
\hline \multicolumn{2}{|l|}{ Ficha 2. Classificando os textos conforme a Tipologia Textual baseada em Contexto } \\
\hline TEXTO & PSS TÍPICO E OUTROS PSS's REALIZADOS \\
\hline Memorando 1 & \\
\hline Memorando 2 & \\
\hline Memorando 3 & \\
\hline Memorando 4 & \\
\hline $\begin{array}{l}\text { Você mudou alguma resposta com relação ao que você respondeu na FICHA 1 da tarefa } \\
\text { 1w? Qual? Justifique. }\end{array}$ \\
\hline Resposta: \\
\hline $\begin{array}{l}\text { Agora observe a linguagem de cada texto em relação aos tempos verbais: existe algo em } \\
\text { comum entre os textos? Especifique. }\end{array}$ \\
\hline Resposta: \\
\hline
\end{tabular}

TAREFA 2: Proposta de tradução direta

Agora vamos traduzir. Copie e cole o texto com o qual você decidiu trabalhar na célula da esquerda na FICHA 1 abaixo. Depois, com o auxílio do PSS das ferramentas apresentadas na UD2 (dicionários bilíngues, linguee, google tradutor, glossários, etc.) proponha uma tradução do texto na célula da direita.

\begin{tabular}{|c|c|}
\hline Ficha 1. Propondo uma tradução direta \\
\hline TEXTO & PROPOSTA DE TRADUÇÃO \\
\hline & \\
\hline
\end{tabular}

Depois de propor uma tradução, vamos refletir sobre o seu processo. Responda as perguntas nas células indicadas.

\section{Ficha 2. Refletindo sobre o processo de tradução}

Quais foram os seus problemas de tradução que emergiram na tradução do memorando que você escolheu traduzir? Pontue, pelo menos 3 (três aspectos).

\section{Resposta:}

Como o fato de já ter identificado o PSS do texto te ajudou na resolução de seus problemas? 


\section{Resposta:}

Relacione as ferramentas que te serviram de ajuda na tradução e qual foi exatamente essa ajuda. Por exemplo:

FERRAMENTA: o dicionário bilíngue; AUXÍLIO: me ajudou a encontrar um termo técnico que não conhecia.

\begin{tabular}{|c|c|}
\hline FERRAMENTA & AUXİLIO \\
\hline & \\
\hline
\end{tabular}

TAREFA FINAL: Reflexão sobre o processo de aprendizado na UD4

Nessa UD você relembrou o que são os PSSs e realizou uma tradução direta. Depois desse trabalho, reflita respondendo a pergunta da FICHA 1 e escreva sua resposta na célula indicadas.

\section{Ficha 1. Refletindo sobre a UD4}

Como o reconhecimento do PSS de cada texto te ajudou no processo de tradução? Explique.

\section{Resposta:}

Em pares, comente com seu colega sobre sua resposta e compare os resultados. Existe semelhanças, diferenças? Pontue-as na FICHA 2 abaixo.

\section{Ficha 2. Refletindo em pares}

Quais foram as semelhanças entre suas respostas e as de seu colega?

\section{Resposta:}

Quais foram as diferenças entre suas respostas e as de seu colega?

\section{Resposta:}

Com base nas respostas acima, teça alguns comentários, levantando possíveis explicações para semelhanças e diferenças.

\section{Resposta:}

Referência metodológica: Profa. Dra. Anabel Galán Mañas, Profa. Dra. Amparo Hurtado Albir (Universidade Autônoma de Barcelona).

Referência teórica: Prof. Christian Matthiessen (Polytechnic University Hong Kong) 